\title{
Germanica
}

GERMANICA

$53 \mid 2013$

Littérature et cinéma dans l'espace germanophone contemporain : jeux intermédiaux, modes de transfert, adaptations

\section{Un film qui vient de loin}

L'Antigone de Sophocle dans la transcription de Friedrich Hölderlin, retravaillée pour la scène par Bertolt Brecht et adaptée pour l'écran par Danièle Huillet et Jean-Marie Straub (1991)

A film that comes from afar: Hölderlin's translation of Sophocles' Antigone revised in Bertolt Brecht's stage adaptation and in the Straub/Huillet film Der Film, der aus der Ferne kam: die Antigone des Sophokles nach der Hölderlinschen Übertragung für die Bühne bearbeitet von Bertolt Brecht in einer filmischen Adaption von Danièle Huillet und Jean-Marie Straub (1991)

\section{André Combes}

\section{(2) OpenEdition}

Journals

Édition électronique

URL : http://journals.openedition.org/germanica/2275

DOI : $10.4000 /$ germanica.2275

ISSN : 2107-0784

Éditeur

Université de Lille

Édition imprimée

Date de publication : 30 décembre 2013

Pagination : 63-88

ISBN : 9782913857322

ISSN : 0984-2632

Référence électronique

André Combes, « Un film qui vient de loin », Germanica [En ligne], 53 | 2013, mis en ligne le 30

décembre 2016, consulté le 06 octobre 2020. URL : http://journals.openedition.org/germanica/2275 ;

DOI : https://doi.org/10.4000/germanica.2275

(c) Tous droits réservés 


\section{Adapter les classiques : enjeux, obstacles, solutions}





\title{
Un film qui vient de loin
}

\author{
L'Antigone de Sophocle dans la transcription de \\ Friedrich Hölderlin, retravaillée pour la scène par \\ Bertolt Brecht et adaptée pour l'écran par \\ Danièle Huillet et Jean-Marie Straub (1991) ${ }^{1}$
}

\section{André COMBES \\ Université de Toulouse-Le Mirail}

\begin{abstract}
... la même tension qui anime leur cinéma et leur marxisme : une tension que pourraient résumer deux noms : Bertolt Brecht et Friedrich Hölderlin : l'artiste qui voulut le plus rigoureusement faire du thêâtre avec la dialectique marxiste et le poète qui fut parmi les premiers à concevoir cette révolution des formes du monde sensible dont le matérialisme marxiste reprit l'idée à sa façon. Brecht et Hölderlin, d'un côté le jeu dialectique des pensées mises en corps pour démonter les mécanismes de la domination et leurs effets sur les dominés ; de l'autre, l'affirmation de la nouvelle communauté sensible et du péril de ceux qui s'aventurent dans son inconnu ${ }^{2}$.
\end{abstract}

Si le titre du film de Danièle Huillet et Jean-Marie Straub (les Straub) nomme, une à une, les étapes des transformations qui mènent

1. - C'est le sous-titre de la version DVD utilisée ici : Danièle Huillet / Jean-Marie Straub, Antigone, allstar MEDIA INTERNATIONAL, 2011. Les Straub en ont publié un découpage sommaire : Huillet/Straub, Antigone - Sophocle / Hölderlin / Brecht, Toulouse, Ombres/cinémathèque française, 1992 (cité par le $\mathrm{n}^{\circ}$ de plan). Il contient, en regard du texte de Brecht, la traduction de D. Huillet, qui laisse délibérément transparaître la langue-source dans la langue-cible, comme le fit souvent Hölderlin.

2. - Jacques Rancière, "L'étrange tribunal », in : Le Monde diplomatique, avril 2003,p. 26. 
de Sophocle à leur film comme autant de variations terminologiques et conceptuelles, c'est qu'il y a là quelques enjeux dans la re-présentation d'un texte ancien - dramaturgiquement fondateur et traitant d'un mythe réputé fondateur -, mais dont le thème principal ambivalent tel que la postérité l'a canonisé (tyrannie vs démocratie, lois écrites vs lois non écrites) semble exiger la réécriture périodique. Pour le Brecht frâ̂chement « rémigré », la conservation et transformation de signifiants autant que de signifiés qui mêlent différents systèmes textuels, scripturaux et visuels se devait, avant toute chose, de « séculariser » et « rationaliser de fond en comble » (durchrationalisieren) ses composantes mythologiques (voir infra). Lorsqu'il réécrivit la pièce de Sophocle dans la traduction d'Hölderlin ${ }^{3}$ fin 1947 dans la ville suisse de Chur, ce fut, pour lui, la condition sine qua non à toute « actualisation » qui se concevait comme l'inscription d'une pratique artistique singulière dans une tradition qui, sur fond des contradictions et conflits sociaux de son temps, se constitue souvent contre d'autres traditions et réinterroge en dernière instance la liaison de l'art et du politique 4 .

Nous examinerons ici la réécriture d'Antigone dans une configuration récente : celle qui confronte, dans la deuxième moitié du vingtième siècle, la théâtralité brechtienne (1947-48) et la cinématographie des Straub (1991-92). Jusque-là cantonnée aux scènes théâtrales - de la grecque aux contemporaines -, la réécriture du mythe d'Antigone accomplit, chez ces derniers, un saut transmédial ${ }^{5}$ qu'on ne saurait pourtant interpréter comme une rupture avec le théâtre - ils conservent

3. - Le texte de Hölderlin et ses « Remarques sur Antigone » seront cités d'après l'édition des Sämtliche Werke, Bd. 5, hrsg. von Friedrich Beissner, Stuttgart, Kohlhammer Verlag, 1965 (cité Beissner $+\mathrm{n}^{\circ}$ de page). Celui de Brecht sera cité d'après la Große kommentierte Berliner und Frankfurter Ausgabe (GBFA), Bd. 8, Stücke 8, bearb. von Klaus-Detlef Müller, Berlin/Frankfurt am Main, Aufbau Verlag/Suhrkamp, 1992 (cité $G B F A, \mathrm{n}^{\circ}$ de vol. $+\mathrm{n}^{\circ}$ de page). Pour ce qui est du texte de Sophocle, auquel il ne sera que rarement fait référence, la version utilisée est : Sophokles, Antigone, übersetzt von Wilhelm Kuchenmüller, Stuttgart, Reclam, $2000^{2}$ (cité : Reclam $+\mathrm{n}^{\circ}$ de page).

4. - Selon K.D. Müller, Brecht reprend littéralement environ 400 vers de la version d'Hölderlin, dans un ensemble qui en compte 1304. « Ganz neu sind insbesondere der Schluß der Auseinandersetzung zwischen Kreon und Antigone und das Ende der Konfrontation Kreons mit dem Seher Tiresias sowie das darauf folgende Streitgespräch mit Kreon und den Alten. » (GBFA 8, 493). Voir aussi Volker Riedel, « AntigoneRezeption in der DDR », in : Brechts Antigone des Sophokles, hrsg. von Werner Hecht, Frankfurt am Main, Suhrkamp, 1988 (cité : Hecht $+\mathrm{n}^{\circ}$ de page).

5. - « Hinsichtlich des auf literarischen Texten basierenden Medienwechsels ist "Transformation" somit zu definieren als eine nach spezifischen medientechnologischen Konditionen vorgenommene Übertragung von deskriptiven, narrativen und argumentativen Elementen eines Zeichensystems (Ausgangstext) in ein anderes Zeichensystem (Zieltext), unter weitgehender Erhaltung der konstitutiven Bedeutungsund Informationsstrukturen » (Michael Schaudig, Literatur im Medienwechsel, München, Schaudig Verlag, 1992, p. 25). 
l'intégralité du texte brechtien et ne le « scénarisent » pas -, mais plutôt comme une interpellation cinématographique d'un texte déjà retravaillé pour la scène. Car, en choisissant de s'adosser à Brecht, les Straub savaient que son travail de réécriture, à la différence de celui d'Hölderlin, était indissociable de son travail collectif de metteur en scène sur sa propre pièce, ce dont témoignent les nombreuses indications scéniques du « Modèle Antigone » (Antigonemodell) ${ }^{6}$ qu'ils connaissaient. Elles pallient largement une absence quasi totale de didascalies, qui semblait apparenter la version brechtienne à celles de Sophocle et Hölderlin. On peut dire que la pièce s'en trouve re-théâtralisée. Le film des Straub est donc un travail prosodique et visuel proprement cinématographique sur le texte de Brecht, qui a pu se souvenir de la mise en scène de Chur telle que les commentaires et les traces écrites et photographiques du Antigonemodell l'ont fixée et non figée. Brecht y insiste longuement dès l'avant-propos $(A M, 75-77)$, car la première mise en scène du texte réécrit ne saurait avoir qu'une valeur prescriptive limitée, ce qui vaut a fortiori pour une adaptation transmédiale.

De Sophocle aux Straub, ce fut donc un long parcours autant inter- que transtextuel, autant inter- que transmédial. Il y aurait à l'origine un texte dramatique grec original, d'abord «transposé/transcrit » (übertragen) par Hölderlin. Puis il y eut la manière typiquement brechtienne de « retravailler » (bearbeiten) hâtivement, en décembre 1947, le texte de Hölderlin, de le prendre pour hypotexte malgré ses « obscurités » qui le rendaient difficilement jouable ${ }^{7}$, voire difficilement compréhensible. Cela concernait par exemple les chants du chœur dont il proposera en 1951 une réécriture qui en explicite et résume le gestus fondamental (GBFA, 24, 351-353) ${ }^{8}$.

Mais de quoi s'agit-il chez les Straub ? De la visitation d'un dispositif textuel et idéologique de la grande mythologie mondiale pour une époque contemporaine qui, depuis longtemps, ne saurait plus le lire, le voir et l'entendre9 ? De l'adaptation d'un texte thêâtral à un écran

6. - J'utiliserai largement ce Antigonemodell 1948 qui comporte 80 photos de scène prises par Ruth Berlau lors de la première représentation à Chur (Suisse), en février 1948, accompagnées des esquisses de la scénographie de Caspar Neher et de très nombreuses indications scéniques ( $c f$. GBFA, 24, 73-168. Cité $A M+\mathrm{n}^{\circ}$ de page).

7. - Brecht note dans son journal le 16 décembre 1947: « Auf Rat von Cas (par Neher) nehme ich die Hölderlinische Übertragung, die wenig oder nicht gespielt wird, da sie für zu dunkel gilt. » (Pour une meilleure orientation dans les différentes éditions, les Journaux de Brecht seront cités: $J+$ date de la note).

8. - Je renvoie ici aux analyses du « retravail » linguistique de Brecht sur le texte d'Hölderlin par Rainer Pohl, "Strukturelemente und Pathosformen in der Sprache », in : Hecht, 245-20. Cf. également l'excellent ouvrage de Dieter Baldo (D. Baldo, Bertolt Brecht « Antigonemodell 1948 », Köln, Pahl-Rugenstein, 1987).

9. - Au moment où il rédigeait quelques remarques sur son « retravail » pour la première de Greiz (RDA), en 1951, Brecht, devenu en 1949 résident d'un pays socialiste, 
qui en recadre les images et les sons sans occulter le travail théâtral concret de Brecht sur une Antigone hölderlinienne davantage vouée à l'approfondissement des possibilités du langage poétique qu'à sa visualisation scénique? De la réaffirmation d'une manière de faire politiquement du cinéma plutôt que du cinéma politique ? En tout cas, certainement très peu d'une conjonction doxale de la littérature et du cinéma, du simple devenir film d'un texte littéraire ${ }^{10}$.

Il faut prendre aussi en compte le fait que, dans le film des Straub, la transmédialité ne fut que seconde, par glissements progressifs pour ainsi dire. Ils montèrent d'abord la version brechtienne à la Schaubühne berlinoise en mai 1991, plus précisément dans l'espace restreint de la salle de répétitions. Puis, à l'été de la même année, ils la mirent à nouveau en scène, avec les mêmes acteurs, mais dans les vastes décors naturels d'un théâtre antique sicilien (Segesta), « scène millénaire pour les classiques du monde », comme le dit le pré-générique du film.C'était un amphithéâtre en ruine qu'ils avaient découvert lors des repérages d'un film précédent (Moïse et Aron), de construction presque contemporaine de la pièce de Sophocle et qui était parmi les mieux préservés d'une île éminemment liée à la civilisation grecque. Cette seconde mise en scène fut une sorte d'avant-film qui permit de travailler concrètement sur site la diction et le placement des acteurs - les éléments profilmiques du futur film donc - et de recadrer les espaces tout en laissant la topographie de plein air d'un théâtre antique tester en partie le dispositif technique de la mise en images. Cela concernera au premier chef le placement de la caméra : une seule position, à même le sol de la scène et à la limite excentrée de l'amphithéâtre pour les plans à hauteur d'homme ou en légère contre-plongée, avec deux trépieds pour la surélever à $4 \mathrm{~m}$ de hauteur dans les assez nombreux plans en plongée. Pas de rails pour des travellings : les seuls mouvements de caméra sont les quelque six panoramiques du film (entre $90^{\circ}$ et $180^{\circ}$ ). Les personnages sont ainsi presque toujours filmés dans le même axe, le plus souvent de profil ou de semi-profil, sauf Tirésias en plans frontaux. Seule change

notait déjà : «Diese Bearbeitungen verhindern nicht den Genuß an den Originalwerken. In nicht allzu ferner Zukunft wird dieser infolge der Schulung des historischen Sinns und des ästhetischen Geschmacks auch den breiten Massen der Bevölkerung möglich sein. » $(G B F A, 24,352-353)$. Un espoir historique que ne partageaient certainement plus les Straub en 1991.

10. - Dans un entretien avec François Albéra publié dans le premier numéro de la revue Leucotheia, qui est dédiée à leur œuvre, J.-M. Straub proclame : « Pour commencer, il faut dire que la conjonction "et", c'est toujours de la connerie : cinéma et histoire, cinéma et littérature, cinéma et musique, tout ça, c'est la fin du monde, la faillite intellectuelle... » (p. 146). Retenons-en ici simplement que le rapport entre cinéma et littérature n'est pas, pour les Straub, de l'ordre de la conjonction, mais bien plus souvent de celui de la disjonction. 
l'échelle des plans : les protagonistes principaux sont le plus souvent filmés en plans rapprochés ou moyens, à l'exception de 14 gros plans : 8 cadrant l'un des « anciens » du chœur et 6 cadrant Antigone, dont 5 à l'identique (profil et légère contre-plongée) ${ }^{11}$. Parallèlement au découpage technique de l'espace, les Straub délégueront à celui des espacestemps opéré par le montage cinématographique ${ }^{12}$ le soin de redistribuer tout en la conservant la conception brechtienne de la « chorégraphie » proxémique, des placements, déplacements, regroupements et postures (Hecht, 23): « Sparsamkeit in den Hin- und Herbewegungen der Gruppen und Figuren sollte die Bedeutung dieser Bewegungen sicherstellen. Die einzelnen Konstellationen, selbst die Abstände, haben dramaturgischen Sinn und in gewissen Augenblicken ist es einer Handbewegung eines Darstellers möglich, die Situation zu verändern. » $(A M, 80)$.

Ce bref état des lieux du tournage montre que les Straub, en réduisant les localisations filmiques pour construire leur espace narratif et leur mode de filmage, entendent parfaitement cadrer le déploiement de la tragédie dans un vaste espace où elle ne doit pas se disperser. De plus, ils donnent au spectateur tout le temps d'organiser leurs perceptions, dans la longue durée des images et de plans apparemment «vides », propice à une mise en rapport attentive des visages et des corps autant qu'à l'articulation des sons et à la captation des bruits ambiants les plus infimes. Car ce parti-pris filmique permet également de prélever, dans les paysages environnant le site de Segesta, des images extérieures à l'enceinte théâtrale et de mettre la parole dialoguée et les corps au centre d'événements élémentaires qui donnent au film une grande légèreté ${ }^{13}$ : le vent, omniprésent dans le film, qui met en mouvement permanent chevelures et vêtures, le ciel et l'impact des variations de sa

11. - Je m'appuie ici en grand partie sur l'excellent ouvrage de Barton Byg, Landscape of Resistances. The German Films von Danièle Huillet and Jean-Marie Straub, Berkeley, University of California Press, 1995, p. 216-235.

12. - Terme à entendre comme le propose le cinéaste Jean-Charles Fitoussi, qui fut l'assistant des Straub: «montage du son et des textes et du cadre et des corps, de l'espace et de la durée - tout cela étant, dans le cas des Straub, capté en un seul temps, celui de l'enregistrement du plan ; manière pour eux de révéler de quoi la réalité se compose, de faire apparaître diversité et oppositions dans l'unité d'un monde unique et sans extérieur » (In : «Le temps d'un retour : notes de tournage de Sicilia », in : La lettre du cinéma, $\mathrm{n}^{\circ} 8$, hiver 1999).

13. - Par cette option, les Straub me semblent au plus près de l'intention brechtienne de ne pas donner à un « thème gigantesque » une « représentation d'un poids plus important» : «Es erfordert die allerleichteste (Behandlung). Bei aller Bestimmtheit der Einzelteile sollte sie im Ganzen etwas Fliegendes haben. [...] Die große Linie sei eine dünne Linie. » $(A M, 130)$. Pour Brecht et $C$. Neher, la légèreté était déjà dans la mobilité des corps et une scénographie minimale. Les Straub y ajouteront celle, immatérielle, du vent et de la lumière naturelle. 
luminosité sur les plantes et les pierres, les vêtements et les visages ${ }^{14}$. Plus que nul autre, ce cinéma, qui n'est en aucune manière assimilable au statisme du « théâtre filmé » des origines, participe, à sa manière, de la « rédemption de la réalité physique » dont parlait, avec un mélange d'accents matérialistes et théologiques, le dernier Kracauer dans sa Théorie du film. Mais, malgré l'omniprésence dans le film de l' " éther » d'un ciel sicilien d'une grande pureté azurée, il ne met pas en images un espace sacré hölderlinien en tant qu'espace néo-mythologique critique du monde contemporain. Pour les Straub, les paysages que montrent leurs films ont donc moins un statut mythologique citationnel qu'une présence physique réelle, avec des connotations symboliques propres à celle-ci (entre le minéral et l'organique par exemple), qui en fait des lieux très matériels chargés d'une histoire spécifique, toujours en excès sur les signifiés de la seule parole dialoguée et de la présence physique des acteurs-personnages qui les habitent sans les investir intégralement. Le changement de lieu implique également un tout autre fonctionnement du texte, en « visite » dans un lieu matériel où il est énoncé dans des paysages et des architectures associables à d'autres temps et d'autres histoires ${ }^{15}$.

De ce théâtre sicilien, Peter Handke a pu dire qu'il était conforme à la « forme [Gestalt] de la tragédie de Sophocle », comme le cinéma des Straub et le théâtre grec étaient « formellement la même chose » 16 . Il est donc un élément essentiel d'une adaptation qui ne fait pas de la revisitation d'un mythe une simple affaire de personnages, de dialogues, de thèmes et d'actions, mais tout aussi bien de topographies lumineuses, autant culturelles que naturelles, qu'on peut imaginer en contraste maximum avec la salle de répétitions de la Schaubühne. Il faudra donc lire aussi l'adaptation des Straub comme une transspatialisation signifiante de la pièce, une sortie de l'espace théâtral - celui de la Schaubühne et celui, tout aussi exigu et moins bien équipé, de la scène en demi-cercle prévue par Caspar Neher pour la représentation de Chur $(A M, 168)^{17}$ - vers celui d'un cinéma d'extérieurs aussi apte à servir de

14. - La scène du récit de la capture d'Antigone par le garde (v. 347 ss.) est ici très significative: c'est un récit entièrement hors champ où la caméra ne montre qu'Antigone en plan rapproché sur fond d'arbre aux feuilles agitées par une légère brise.

15. - Je reprendrais volontiers à mon compte cette réflexion d'Alain Badiou, selon laquelle, au cinéma et surtout chez les Straub, «l'idée visite le sensible », mais ne s'y « incarne » pas (cf. Petit manuel d'inesthétique, Paris, Seuil, 1998, p. 124). p. 67.

16. - Cf. Peter Handke, « Kinonacht », in : Die Zeit, 13 novembre 1992, n47,

17. - Comme elle le reconnaît elle-même, les photos de R. Berlau, prises en légère plongée pour améliorer la "plasticité des groupes et des mouvements », souffrent d'un éclairage trop faible pour créer cette « aire de jeu bien éclairée » que voulait Brecht et qui contraignait les acteurs à « se mouvoir dans des couloirs d'ombres et brouillards 
cadre à l'intense intériorité subjective des antagonismes politiques de la version brechtienne que l'intimité de petits espaces scéniques. Une extension intermédiale de l'espace scénographique du théâtre, comme les photographies d'un théâtre antique utilisées par les Straub pour leur décor de la Schaubühne, ne produit pas les mêmes effets. Mais il ne s'agit pas, pour eux, de se contenter d'un effet de site qui baignerait le texte d'une lumière mythologique plus crue, reliant imaginairement les protagonistes humains, qui se meuvent dans l'espace symbolique de la scène de plein air, et les protagonistes divins de la mythologie grecque, habitant, invisibles, l'espace panthéiste de la nature sicilienne ${ }^{18}$.

La sortie de l'espace théâtral habituel, qui n'abolit pas une certaine théâtralité fondamentale de la mise en images d'un texte dialogué, pourrait s'autoriser de quelques vers de ce « Nouveau prologue [Prolog] d'Antigone », rajouté en 1951 pour une représentation à Greiz (RDA), à la place de celui (Vorspiel) de la version de 1948 à Chur : Brecht y avait introduit implicitement un double espace où l'exiguïté physique de la scène de Chur avait pour extension l'espace idéel induit par sa relecture du mythe. Dit par Tirésias, avec la présence muette de Créon et d'Antigone, il se terminait par une adresse épique aux spectateurs :

Und nunmehr / Werdet ihr uns und die anderen Schauspieler / Ein um den andern den kleinen Schauplatz / Im Spiele betreten sehn, wo einst unter den / Tierschädeln barbarischen Opferkults / Urgrauer Zeiten die Menschlichkeit / Groß aufstand.

Ainsi, ce que montrent les photos de Ruth Berlau et la description de la scénographie de Neher (AM, 77-78 et 168), c'est à la fois un théâtre de la réduction apparente des signes scéniques à l'essentiel de ce qu'exige le gestus fondamental de la pièce et une charge symbolique importante de la scénographie ${ }^{19}$. Qu'une « petite scène », plongée dans une pénombre assez involontaire qui la rapetissait, puisse contenir la vaste métaphore des temps immémoriaux de la barbarie des sacrifices dans lesquels " émergea/se dressa, pleine de grandeur, l'humanité » semblait donc appeler un nouvel espace. On peut ainsi émettre l'hypothèse que, dans le transfert de la pièce de cette «petite scène » à un

lumineux incontrôlables » (cf. GBFA, 25, p. 82).

18. - On pourrait citer ici, en ce sens, l'optique de Cesare Pavese, que les Straub ont longuement pratiqué et adapté : « Es ist nötig, dass die Landschaften - besser die Orte, das heißt der Baum, das Haus, der Weinstock, der Pfad, die Schlucht und so weiter - leben wie Personen, wie Bauern, und das heißt, daß sie mythisch sind. » (Lettre du 27 juin 1947 à Fernanda Picano, citée d'après la postface de Johannes Hösle à l'édition allemande des Gespräche mit Leuko, Düsseldorf, Claassen, 1989, p. 217).

19. - L'aire de jeu était délimitée par quatre pieux sur lesquels étaient accrochés des crânes de chevaux morts, symboles citant une antique barbarie, accompagnés de certains attributs allégoriques liés à différents personnages, le glaive de Créon par exemple. 
vaste site grec illuminé par le soleil sicilien, se noue une bonne part du retraitement du texte-scène par le texte-écran.

Même s'il sera ici question du travail des Straub sur le texte et les indications de mise en scène de Brecht, du passage de la scène brechtienne à l'écran straubien donc, on peut commencer par inscrire dans chacune des trois réécritures mentionnées dans le titre du film des éléments du contexte de leur production qui font apparaittre des connexions politiques souterraines. 1794-1804 : pour Hölderlin, c'est la contemporanéité et l'immédiat après-coup de la Révolution française et le temps d'un « retournement patriotique » (vaterländische Umkehr) ${ }^{20}$ nourri de son propre mythe grec d'une germanité rénovée dans son éthique et sa politique ${ }^{21}-1948$ : pour un Brecht préoccupé de faire un bilan sévère de l'Allemagne de l'après-guerre et de la situation artistique et idéologique de ses théâtres après la traversée des «temps obscurs » (cf. $A M, 73$ ), c'est l'inclusion, dans les notes de journal parallèles à la réécriture, d'une critique radicale du rôle du capitalisme impérialiste dans les entreprises nazies - 1991 : pour les Straub, c'est une date que le spectateur pouvait accoler à la toute récente réunification allemande qui restaurait une continuité que Brecht (comme les Straub ?) suspectait d'être porteuse de nouveaux « déchirements ${ }^{22}$.

Les trois réécritures pourraient donc illustrer une récurrence que la thèse de l'avant-propos du Antigonemodell formulait brièvement : «Es ist ein Drama, das kämpferisch in die damaligen griechischen Zeitgeschehnisse eingreift » $(G B F A, 24,349)$. Pour Brecht et les Straub, qui n'ont pas choisi au hasard sa version de la pièce, cette intervention politique « combative », qu'il s'agit de refaire émerger du texte de Sophocle à travers la transposition d'Hölderlin, ne peut faire l'économie d'adjonctions directement ou indirectement actualisantes. Chez le Brecht de 1948, elle sera d'abord le fait du Vorspiel déjà mentionné, qui est une action à part entière : moins centrée sur le « rôle de l'usage de la violence dans le déclin du sommet de l'État» $(A M, 74)$ que sur l'acte résistant d'Antigone, deux phénomènes qui seront réinterrogés dans la diégèse de la pièce. Ce Vorspiel est une sorte de long poème épico-dramatique qui recentre le tragique autour d'événements calqués sur des réalités fréquentes dans les derniers jours de la guerre : le retour

20. - Cf. Beissner, 295.

21. - Je renvoie à la traduction allemande (à cause des citations originales) du livre remarquable de George Steiner, Die Antigonen. Geschichte und Gegenwart eines Mythos, München, Hanser, 1988. Sur Hölderlin, $c f$. p. 86 et suiv.

22. - En janvier 1948, Brecht se montre préoccupé par les formes que peut prendre l'unité allemande d'après-guerre, réflexions qui préfigurent certains discours critiques sur la réunification de 1990 : «Zugleich kann dieses Deutschland nicht mehr begriffen werden ohne Dialektik, denn seine Einheit muß es durch weitere Zerreißung erkämpfen, die Freiheit kriegt es diktiert usw. usw. » (J., 6 janvier 1948). 
d'un frère soldat qui a déserté un jour d'avril 1945, son assassinat par un SS qui le pend à un crochet, la réaction différente de deux sœurs, entre passivité résignée et résistance, l'une des grandes problématiques du théâtre brechtien des années nazies, que l'on pense à Furcht und Elend des Dritten Reiches (1937-38) ${ }^{23}$.

Ce premier prologue donnait une figure historique concrète à un destin dont Brecht cherche également à supprimer la dimension de «"Moira" grecque » 24 . Brecht entendait, au contraire, « séculariser » une conception antique selon laquelle «l'homme est plus ou moins livré aveuglement au destin, il n'a aucun pouvoir sur lui », et lui opposer un des axiomes de la modernité : «le destin de l'homme, c'est l'homme lui-même » (GBFA, 24, 349-350). Dit autrement : «Antigone, zum Tode verurteilt, fordert die Alten auf, anstatt zu ihr von der Macht des Schicksals zu sprechen, die Macht des Tyrannen zu brechen. » (Hecht, 25).

Les Straub font, quant à eux, commencer leur film par la longue plainte d'Antigone à sa sœur Ismène, comme chez Sophocle - chez qui elle est cependant « prologue » - et Hölderlin - chez qui elle est la première scène d'un premier acte. Mais ils ajoutent une sorte d'épilogue extra-diégétique qui cite une intervention de Brecht au Congrès viennois pour la paix en 1952 :

Das Gedächtnis der Menschheit für erduldete Leiden ist erstaunlich kurz. Ihre Vorstellungsgabe für kommende Leiden ist fast noch geringer. / Diese Abgestumpftheit ist es, die wir zu bekämpfen haben. / Denn der Menschheit drohen Kriege, gegen welche die vergangenen wie armselige Versuche sind, und sie werden kommen ohne Zweifel, wenn denen, die sie in aller Öffentlichkeit vorbereiten, nicht die Hände zerschlagen werden.

C'est un long plan muet d'insert textuel, avec un bruit de moteurs d'hélicoptères en off, qui rompt avec l'économie dramaturgique du film et propulse la pièce dans une actualité pérenne : celle des angoisses de l'humanité face aux guerres à venir et à leurs dévastations inouïes. Ils peuvent ainsi relier les mises en garde prémonitoires de Brecht à la nouvelle conjoncture guerrière de $1991^{25}$.

23. - Dans une version ultérieure du prologue, la passivité craintive d'Ismène change du tout au tout : il ne s'agit plus de couper la corde à laquelle est pendu le frère avec un couteau, mais d'enfoncer celui-ci dans le corps du SS qui l'a assassiné avec l'assentiment de la sœur hésitante, action qui ressoude l'unité des deux sœurs autour d'une action plus violente que celle de la diégèse elle-même : «Ismene : Und als sie ihm das Messer eintrieb / Da war mir meine Schwester lieb » $(G B F A, 8,492)$.

24. - Cf. la lettre de Brecht de décembre 1947 à son fils Stefan (citée in : Hecht, 19). Le terme de «Moira» se trouve également chez Sophocle dans le grand chant du chœur sur la « force du destin » qui suit la dernière apparition d'Antigone (Reclam, 42-44). Hölderlin traduit par «grand destin», tandis que Brecht supprime tout le chant.

25. - Straub a pu provoquer quelque irritation, lors de la première d'Antigone à 
Un tel épilogue peut ainsi apparaître comme le prolongement logique des signifiés implicites du long titre choisi par les Straub. Ils inscrivent leur «adaptation » dans une sorte de continuité benjaminienne de la longue histoire des catastrophes humaines - celles qui nouent, comme le mythe originaire, les tueries familiales aux guerres civiles et aux guerres impériales - à un moment où l'effondrement du bloc soviétique et le «tournant » de la réunification allemande pouvaient en laisser espérer la fin. C'est cette continuité qui laisse implicitement ouverte la possibilité d'une nouvelle réécriture et d'un allongement potentiellement infini du titre de leur film : le mythe d'Antigone et sa dimension prophétique font du deuil un affect de grand avenir tant que pèseront sur l'humanité les menaces de guerres nouvelles et « si à ceux qui publiquement les préparent on ne coupe pas les mains ${ }^{26}$. Rappeler ce contexte, c'est anticiper certains jugements critiques sur la version de Brecht et sa reprise par les Straub, comme celui de Handke, qui jouait le modernisme poétique et le sens de la tradition tragique grecque de Hölderlin contre le didactisme politique de la version de Brecht ${ }^{27}$.

On peut maintenant examiner les significations multiples du « retravail » brechtien - texte et mise en scène de Chur -, telles qu'on peut les reconstituer à l'aide du Antigonemodell, avant d'analyser leur « adaptation » dans la mise en scène et en images du film des Straub. Celles qui sont au fondement de la relecture/réécriture d'Antigone sont indissociables de la théorie brechtienne du nazisme. Les notes de journal parfaitement contemporaines de ce premier travail théâtral dans l'aire linguistique germanique, que les Straub citent largement dans le programme de la représentation de la Schaubühne, montrent une évidente préoccupation (GBFA, 27, 255-275) : la réécriture d'Antigone, pièce réputée emblématique de la collision entre tyrannie et démocratie, est indissociable d'une interprétation de la situation idéologique et morale héritée du nazisme et de la critique du discours dominant chez ceux des intellectuels occidentaux qui rejetaient le fascisme au nom de ces valeurs démocratiques de la « civilisation occidentale » que la réécriture d'Antigone va servir à réinterroger. Pour Brecht, ce rejet est symptomatique des refoulements et occultations qui rendent aveugle au fait que « la perte des libertés individuelles sous le capitalisme » fait de celles-ci une pure fiction tant qu'elle est référée à un nazisme qui serait l'antagoniste de la démocratie occi-

la Schaubühne, en interpellant le public sur la guerre en Irak.

26. - Dans sa dernière tirade, beaucoup moins focalisée sur le tragique de son destin que chez Sophocle et Hölderlin, Antigone prophétise une longue suite de morts sans sépultures, sortant de l'espace mythique du conflit de Sophocle pour entrer dans celui de l'histoire sans fin des calamités guerrières : «Euch beweine ich, Lebende / Was ihr sehen werdet / Wenn mein Auge schon voll des Staubes ist. » (v. 849-851)

27. - Cf. « Kinonacht », op. cit. De plus, Handke attribue aux Straub les inserts brechtiens de passages de Goethe et de Pindare. 
dentale et non « son autre phase naturelle, dans laquelle la dictature de la bourgeoisie se dévoile intégralement » (J., 16 mars 1948). Démasquer le rôle de la bourgeoisie allemande dans une guerre cataclysmique qu'on ne saurait plus seulement nommer « hitlérienne » $\left(J ., 1^{\text {er }}\right.$ mars 1948) exige de montrer qu'on ne peut dénazifier la bourgeoisie qu'en la désembourgeoisant : « Das deutsche Bürgertum "entnazen" heißt, es entbürgern » (J., $1^{\text {er }}$ janvier 1948).

La nouvelle figure d'Antigone, forgée par les nouvelles significations qu'imposent en 1947-48 les dévastations inouïes de la dernière grande catastrophe guerrière, excèdera donc la simple défense des lois immémoriales non écrites contre un pouvoir d'État qui se légitime d'un divin par lui instrumentalisé. Il excèdera ainsi le propos de la version inaugurale : mettre au centre des réflexions de la polis les conséquences d'un conflit entre les lois coutumières non écrites et celles édictées par les gouvernants de la cité des hommes, toutes deux aimant à se réclamer d'une origine divine. Antigone y représenterait un droit plus humain et plus intangible, en fin de compte antagonique du droit plus conjoncturel que le pouvoir d'État instaure par sa législation. C'était la problématique canonique de la «collision » structurelle des deux droits - pointée par Hegel, l'ancien condisciple d'Hölderlin - qui serait au cœur du tragique d'Antigone ${ }^{28}$.

Le début d'un avant-propos non retenu pour le Antigonemodell montre que, dans une première phase de sa réécriture, Brecht a pu partir de cette vision-là, majoritairement entérinée par la postérité des exégèses politiques de la pièce: " Die Antigone des Sophokles ist die betonte Absage an die Tyrannis und die Hinwendung zur Demokratie », écrit-il dans des remarques sur Antigone ${ }^{29}$. L'Antigone " sécularisée " de Brecht en fera un conflit moins abstrait entre deux pratiques exclusivement humaines : œuvres de mortels, les droits sont modifiables par d'autres mortels (v. 359-361).

Nous avons vu par ailleurs que l'excipit du prologue de 1951 opposait à la barbarie archaïque non plus la démocratie, mais l'humanité, soit une culture centrée sur l'humain, sorte de dialectique infernale entre culture et barbarie dont Antigone est à la fois l'instrument et la victime et dont le nazisme représentait pour beaucoup, dans les années trente et quarante, l'apogée historique :

Was im zentralen Konflikt des Antigone-Stücks verhandelt wird, nämlich der Verstoß gegen die agrapta nomina, die ungeschriebenen

28. - « Antigone verletzt das Recht des Staates, Kreon das der Familie. Die Antinomie zweier gleichberechtigter Prinzipien macht das Wesen der Tragödie aus. » Cf. Sophokles Antigone Erläuterungen und Dokumente, hg. von Marion Giebel, Stuttgart, Reclam, 2003, p. 60-61. Cf. également G. Steiner, Die Antigonen, op. cit., p. 54 et suiv. 29. - Cf. GBFA, 24, 349 . 
Gesetze, geht weit über die Verletzung der geheiligten Bestattungspflichten hinaus. Eifersucht und Rivalität, Familienzwist, Blutrausch, Wutexzesse und Rache, Vatermord, Gattenmord, Kindermord, Kindes-Aussetzungen und grausame Einkerkerungen, archaische Opferriten, unerlaubte Sexualbeziehungen und illegitime Usurpationen, Verletzungen von Gastrecht und eine erschreckende Anzahl von Selbstmorden von Ehefrauen (Ino, Iokaste, Eurydike) bis zu beiden Söhnen Kreons - dies alles zusammen zeigt eine Dynamik destruktiver Energien, die jede kulturelle Ordnung in ihren Grundlagen zersetzt. [...] Dies ist es, was Hölderlin die „reißende Zeit“ nannte und den „Geist der ewig lebenden ungeschriebenen Wildniß und der Todtenwelt". Es ist das aus der Mitte der Kultur ausgebrochene Chaos. Die Barbarei.

Antigone ist das ,Kind“ (pais) dieser barbarischen Verkettungen. Ihr Begehren und ihr Wahn ist es, um es mit den Worten Kafkas zu sagen, das „Hinausspringen aus der Totschlägerreihe“" zu wagen ${ }^{30}$.

Intéressé, dans le mythe, par ce « saut» hors de l'histoire familiale et sociale des atrocités, Brecht ne va pas se satisfaire d'une simple alternative entre culture et barbarie, qui décalquerait simplement celle entre démocratie et tyrannie et qu'avait privilégié, en 1935, un « Congrès pour la défense de la culture » devant lequel il avait proclamé l'urgence de parler aussi des rapports de propriété, position réaffirmée, nous le verrons, dans sa réécriture d'Antigone. Ce qui ne signifiait pour autant vouloir occulter la barbarie ; il suffit de ne pas la mythifier en la référant à un destin supra-humain - la malédiction des Labdacides par exemple - et de ne pas en faire un « état d'exception » conjoncturel qui désarmerait tout penser politique sur celui-ci ${ }^{31}$.

On peut en repérer les traces dans la réécriture de la fin du célèbre stasimon du chœur : «Ungeheuer ist viel. Doch nichts / Ungeheuerer, als der Mensch », qu'Hölderlin avait placé au début de son acte II. Si Brecht ne reprend pas cette mise en exergue formelle, il lui conserve sa centralité ${ }^{32}$, modifiant néanmoins profondément le texte de Hölderlin à la fin du stasimon en ajoutant des vers qui font dériver plus explicitement le sens laudatif de l'anaphore initiale vers le «monstrueux »33. Quand

30. - Hartmut Böhme, "Götter, Gräber und Menschen in der "Antigone" des Sophokles », in : Gisela Greve (Hg.), Sophokles. Antigone, Tübingen, ed. Diskord, 2002, p. 93-124.

31. - Cf. la thèse VIII de Über den Begriff der Geschichte de son ami Walter Benjamin que Brecht avait lu dès 1940.

32. - Dans le film (plan 31), seuls les tout premiers vers du stasimon sont énoncés dans le champ (plan d'ensemble en plongée du chœur). Les vers suivants le sont hors champ, comme nombre d'interventions du chœur, la caméra cadrant l'une des bandes dallées du sol de terre battue. C'est un plan apparemment vide, mais plein d'une vocalité sans visage, comme en retrait d'un texte qui fait résonner l'ambivalence mortifère de l'humain.

33. - Il le précise dans ses «Anmerkungen zur Bearbeitung » $(G B F A, 24,351)$ : 
l'homme perd toute mesure et devient un loup pour les autres mais aussi pour lui-même, quand il contraint « la nuque de son semblable » à se courber sous son joug tandis que celui-ci lui « arrache les entrailles », quand il dresse des murs autour de sa propriété et abat ceux des autres, « ouvrant le toit à la pluie », quand l'humain ne signifie plus rien pour lui, alors il devient « un monstre pour lui-même » (v. 300-310). Comme ce fut le cas dans cette « orgie sanglante la plus énorme, le plus grand déchaînement des forces destructives, collectives et personnelles » qu'était et que sera toujours pour Brecht la Seconde Guerre mondiale (J., 20 avril 1948). En contrepoint scénique de la barbarie "monstrueuse » proférée sur l'aire de jeu, le garde de la mise en scène de Chur attachait sur le dos d'Antigone la planche qu'elle va conserver jusqu'à la fin de la scène et qui à la fois la « courbe », entrave ses mouvements et soutient sa révolte. "Das Brettschleppen macht Antigone zu einem Unruhezentrum, da es ihre Reaktionen und Aktionen physisch groß umsetzt. [...] Im Kampf scheint das Brett leichter zu werden » $(A M$, 104 et 103-111) ${ }^{34}$. Pas de «monstruosité » qui ne recèle à son insu les conditions matérielles et morales d'une résistance de l'humain.

Pour ne pas laisser la barbarie se réinvestir de mythologie, le propos de Brecht, tel que les notes suisses du Journal le précisent (J., 2 mars 1947 et 5 janvier 1948), fut de faire subir une torsion matérialiste à la fable et aux protagonistes principaux. Cette tâche complexe se conformait aux remarques initiales sur la fable originaire car, a priori, la pièce ne pouvait se voir conférer une « certaine actualité » qu'à condition de procéder à sa « rationalisation systématique » (Durchrationalisierung) $(A M, 74)$, sinon sa place était dans « les cimetières barbares de crânes de chevaux morts » (J., 18 janvier 1948). La guerre de Thèbes contre Argos devient ainsi une guerre de conquête impérialiste pour un " minerai gris », qui la rapproche des guerres nazies afin de mieux interroger ce réel-là à travers l'antique fiction. Sa cruauté et sa violence doivent être montrées comme une violence des maîtres de l'État qui ont réussi à entraîner le peuple de Thèbes dans une guerre impériale contre Argos, rendant caduc le droit en vigueur et en créant un nouveau, placé non plus sous l'égide des dieux, mais sous le signe d'intérêts bien terrestres:

« Der Mensch, ungeheuer groß, wenn er die Natur unterwirft, wird, wenn er den Mitmenschen unterwirft, zum großen Ungeheuer ».

34. - Chez les Straub, pas d'accessoires pour alourdir les tuniques agitées par la brise. Le corps d'Antigone est toujours droit, plein de « grâce et de dignité », mais sans excès. Ce qui l'opprime ne marque pas ses postures, très peu également sa mimique et sa diction, et pas du tout sa gestuelle : la langue de l'oppression et de la résistance ne s'exprime pas dans le corps. Chez son antagoniste, Créon, c'est autant que la conflictualité verbale plus exacerbée - contre Antigone, Hémon, Tirésias et même le chœur - qui infléchit la diction et mobilise le plus l'expressivité du corps : les mains et bras en particulier. 
« Krieg schafft neues Recht», dit Créon au chœur des anciens (v. 1089). Il y a là une nouvelle articulation du conflit entre Thèbes et Argos qui doit montrer le caractère indissociable de la déchéance du sommet de l'État thébain et de son incapacité à organiser à la fois son économie et ses guerres. Car le propre de la violence et de la «cruauté » de la guerre de conquête, c'est qu'elle "nécessite aussi d'être cruel envers son propre peuple » $(G B F A, 24,350)$ : dilemme fondamental d'un pouvoir qui entend mener une guerre de pillage vers l'extérieur avec l'aide de ceux qu'il a pillés de l'intérieur («Les pillés sont invités à piller », $J$., 5 janvier 1948). La violence cruelle déchaînée envers Argos fait alors « exploser », à Thèbes, la force « humaine élémentaire » qu'elle avait artificiellement comprimée, sapant les fondations de l'entreprise guerrière et précipitant sa perte $(J ., 5$ janvier 1948$)$.

C'est ainsi que Brecht, s'appuyant sur sa propre analyse des guerres puis de la débâcle de l'État nazi - l'avant-propos du Antigonemodell fait d'Argos le lieu d'un « brusque retournement », un « Stalingrad d'aujourd'hui »35 $(G B F A, 24,350)-$, relit l'« intrigue [Begebenheit] Antigone-Kreon » : elle n'est plus centrée, comme chez Sophocle et Hölderlin, sur la vengeance d'État post-guerrière de Créon à l'encontre de la « coutume humaine » qui exigeait une sépulture, même pour celui qui avait trahi la cité (Polynice), vengeance qui finissait par décimer sa propre famille et en faire une loque repentante à la fin de la pièce. Toute la problématique d'une cruelle violence d'État, inséparable de sa criminelle impéritie et de la débâcle de sa classe dominante ${ }^{36}$, doit être dépouillée d'une conception qui ne saisit pas ce qu'il y a en fin de compte de «non pratique » dans des guerres à la fois impérialistes et civiles, comme celles menées par le nazisme, qui compensent précisément leur échec par une débauche de violence. La morale de Créon (ou de Goebbels et Hitler), dit encore une note de journal de janvier 1948, c'est donc plutôt la mobilisation des dernières réserves sous les oripeaux d'une guerre qui devient «totale »- on pense à celle proclamée par Goebbels quelques jours après Stalingrad dans le palais des sports berlinois -, comme l'est le naufrage de l'État qui la mène: «Dieser Einsatz der letzten moralischen Reserven mißlingt und beschleunigt den Untergang [...]. Der Untergang wird sozusagen umso totaler. » $\mathrm{Ce}$

35. - L'avant-propos du Antigonemodell mentionne un décor envisagé, montrant une « ville en ruine », peut-être l'une de celles reproduites dans le Journal des années de guerre puis la Kriegsfibel de 1955 (AM, 78).

36. - Le Journal montre à l'évidence l'intrication des réflexions sur la débâcle du nazisme, qui fut celle de la classe bourgeoise autant que de Hitler (« Die Grausamkeit der nazistischen Staats- und Kriegsführung war genau das, was die Bourgeoisie brauchte, sie empfahl ihr Hitler. », J., 1er mars 1948), et de celles sur la problématique centrale d'Antigone, réflexions nourries par Der SS-Staat de Eugen Kogon et les mémoires de Goebbels (J., 20 avril 1948). 
pourquoi l'accent nouveau mis sur une trinité négative (pouvoir tyrannique / guerre impérialiste / massacres intérieurs autant qu'extérieurs ${ }^{37}$ ) signifie concrètement une certaine obsolescence des rites immémoriaux de sépulture ${ }^{38}$ et, partant, l'abolition des lois morales, écrites ou non. C'est la teneur des dernières déclarations d'Antigone au chœur.

Cependant, les analogies politiques avec le présent apparurent rapidement aussi frappantes que problématiques si on ne remettait pas en cause l'héroïsation de la protagoniste principale que des siècles d'exégèses et de réécritures avaient promue « grande figure de la résistance dans le drame antique ». Celle-ci, dit Brecht, ne saurait, une fois « rationalisée », « représenter » celles des figures de la résistance au nazisme qui « (nous) semblent les plus importantes » $(A M, 74)$ et que la mémoire collective dominante d'après-guerre s'est empressée de refouler : pour lui, c'était la résistance communiste plus que le 20 juillet 1944 des Beck, Goerdeler et Stauffenberg qui, comme son Antigone, « ont bien trop longtemps mangé le pain cuit dans d'obscures régions [im Dunkeln] » $(J, 12 \text { janvier 1948) })^{39}$. Faisant, à l'instar du chœur, partie de la classe dominante de Thèbes et donc ayant longtemps été partie prenante des modalités de cette domination, Antigone ne peut pas en être totalement exceptée : «Erst als die Gewalt, die vom Haus Ödipus ausgeteilt wurde, in dieses Haus zurückschlug, erwachte sie. » $(G B F A, 24,352)^{40}$.

Ce qui vaut bien davantage pour le chœur. De par son importance idéologique et scénique, le chœur a donc dû, lui aussi, être réécrit et mis en scène avec une attention particulière. Intéressé, sur un plan plus formel, par le caractère épique de la « double fonction » dramaturgique du chœur antique, « commentateur et protagoniste » $(A M, 102)$, par son statut traditionnel de médiateur entre les protagonistes, dont il interrompt et relance les épisodes, et le public, Brecht en réoriente néanmoins la signification globale. Contrairement à Sophocle, il souligne d'abord que leur statut d'anciens de la cité («Die Alten ») n'en fait pas les dépositaires d'une sagesse non partisane qu'illustraient, dans la tragédie grecque, les strophes et antistrophes de ses chants. D'où l'importance de trouver une figuration scénique différente des mises

37. - Trinité déclinée ainsi par une réplique de Tirésias face à Créon ajoutée par Brecht : « Denn keiner weiß im Krieg, was er behält. / Sei's Silber, seien's Söhne, sei’s Macht. » (v. 973-974).

38. - «Andere Körper, zerstückte / Werden euch liegen, unbestattet, zu Hauf um den / Unbestatteten. » (v. 842-844).

39. - Il mettra la remarque, presque mot pour mot, dans la bouche du chœur lors de la disparition d'Antigone (v. 865-867).

40. - Ce qui signifie, pour la direction d'acteurs, que l'actrice qui joue Antigone est, plus que d'autres, vouée au style épique dénué de toute empathie, car elle doit résister à la « tentation » d'inspirer de la pitié au spectateur et de lui voiler « les dissensions des dominants, auxquels (elle) appartient » $(A M, 106)$. 
en scène traditionnelles : « Es wurde übrigens darauf verzichtet, die Alten zu Greisen zu machen, da weder Weisheit noch Poesie hauptsächlich bei Greisen zu finden sind, und um Kriege zu machen, muß einer nicht alt sein, sondern nur zu den Herrschenden gehören. » $(A M, 102)^{41}$. C'est une option également retenue, à une exception près, par la distribution des Straub, qui maintiennent néanmoins le statisme scénique habituel des chœurs grecs. Mais Brecht en fait surtout une figure essentielle de la « représentation des Grands de Thèbes » et, par extrapolation, de la grande bourgeoisie de la polis. Il est d'ailleurs déjà nommé tel par Sophocle : « riches citoyens » (reichbegüterte Bürger) (Reclam, 39). Hölderlin en fait des « vielbegüterte Männer »(Beissner, 261), formule reprise par Brecht (v. 774). Même s'il peut, chez lui, prendre ses distances envers Créon dans son incitation à la mansuétude envers Antigone et la critique ambivalente d'une guerre désastreuse - allusion vraisemblable au basculement d'une partie des couches dirigeantes allemandes à partir de $1943^{42}$-, il est jusqu'à la fin le soutien indéfectible du trône, accompagnant Créon dans sa sortie de scène «vers la cité qui s'écroule », tels ces irréductibles nazis des derniers jours du bunker: «Folgten dem Führer auch jetzt, und jetzt in Verfall und Vernichtung », dit l'indication scénique $(A M, 159)$.

La dernière grande réplique d'Antigone à l'adresse du chœur aurait ainsi pu s'adresser à la grande bourgeoisie allemande - de Krupp à l'IG Farben - impliquée dans les principales entreprises guerrières du régime ${ }^{43}$ :

Nicht, ich bitte euch, sprecht vom Geschick. /... ... Ihr, die dem Kreon den Krieg / Über unheimische Marken schleppet, so viele / Schlachten auch dem glücken die letzte / Will euch verschlingen. Ihr, die Beute rieft, nicht / Volle Wagen werdet ihr kommen sehen, sondern / Leere.

41. - Dans la grande confrontation entre Créon et Antigone, le chœur de Chur était d'abord regroupé autour de Créon, jusqu'à la sortie de scène de la seconde qui est le moment où il prend quelques distances avec le pouvoir, l'incitant à la clémence. Dans le film, le chœur est d'entrée installé dans un espace et un angle de prises de vue qui lui est propre (côté gradins, selon son placement antique habituel).

42. - Créon a beau jeu de railler l'inconséquence de ces « hésitants », comme les nomme Brecht, à se dresser contre son pouvoir alors qu'ils ont accepté de profiter des produits de ses pillages : «Undankbare! Fresser der Fleische, aber / Des Kochs blutige Schürze gefällt nicht » (v. 1092-93).

43. - « Zur Frage der Ächtung derer, die mitgemacht haben: es war richtig, während des Kriegs den Krieg dem deutschen Volk als den Krieg Hitlers zu bezeichnen. Jetzt muss der Krieg als der Krieg der deutschen Bourgeoisie bezeichnet werden, von Hitler im Auftrag geführt. » (J., $1^{\text {er }}$ mars 1948$)$ 
Voilà la nouvelle définition non mythifiante du destin qu'Antigone, jusque dans la signifiance poétique de sa langue ${ }^{44}$, propose dans son ultime tirade et qui, à elle seule, pourrait justifier le choix de la mise en garde brechtienne explicite dans l'épilogue straubien du film.

La mise en scène de Chur avait exhaussé, par divers moyens, la soumission du chœur au pouvoir tyrannique : après s'être paré d'une couronne de laurier pour fêter « la victoire au riche butin » (v. 106) (photo $A M, 95)^{45}$, il répondait à Créon par un acte d'allégeance marqué qui légitime la loi du tyran dans toutes les acceptions du nómos grec, législation et droit coutumier : « Nach jeglichem Gesetz steht dir wohl $\mathrm{zu}, /$ Mit uns, ob tot, ob lebend, zu verfahren » (v. 213-214). Une esquisse de Neher $(A M, 164)$ montrait également combien la position des choreutes pouvait être courbée dans une soumission qui agglutinait les corps alors que les Straub préfèrent leur maintenir en permanence une posture droite et distante, laissant à la diction et au texte le soin d'exprimer cette soumission dans toute son ambiguïté.

Le statut d'acolyte du pouvoir était signifié jusque dans le maquillage. Maquiller à très gros traits, "plus que de coutume », mais comme au tout début du théâtre grec, il doit rendre lisibles les effets de ce pouvoir sur les visages : " zum Beispiel bei den Alten die Verwüstungen, welche die Gewohnheit zu herrschen in den Gesichtern anrichtet und so weiter » $(A M, 80)^{46}$. Dans cette même optique, la représentation de Chur semble avoir travaillé la mobilité scénique du chœur, absente du film: en agrégeant ou désagrégeant les groupes, ses placements et déplacements ont des significations cryptopolitiques qui redéfinissent le statut scénique d'un groupe qui, dramaturgiquement, constitue d'abord l'entourage immédiat de Créon, puis prend ses distances avec le tyran, opérant même un mouvement menaçant lorsque la victoire annoncée prématurément s'avère être le prélude à la catastrophe. Parallèlement à cette mobilité inhabituelle du chœur, les indications scéniques en réduisaient le caractère verbalement compact en répartissant par deux fois les répliques entre ses quatre membres alors qu'aucune didascalie de la pièce ne le stipulait : dans le chant à la gloire de Bacchus, « Geist der Lüste im Fleisch », accompagné à Chur d'un martèlement de thyrses et

44. - Notons qu'on perçoit bien ici le statut sémantique capital des césures de fin de vers (voir infra) quand «so viele » s'en trouve déterminer à la fois les «batailles », que l'enjambement aurait seules exhaussées, et les « marches étrangères ».

45. - Les Straub font débuter la scène, filmée en plan général et en plongée, par un coup frappé avec le thyrse de Bacchus qui semble inaugurer une autre scène, plus dionysiaque.

46. - Les Straub, fidèles à leur conception du visage cinématographique du personnage, au plus près du visage réel de l'acteur et de la lumière naturelle qui l'éclaire, ne le maquillent pas. Ils ne font donc aucune référence à cette théâtralité aussi ancienne que la tragédie, avant l'introduction des masques. 
prononcé hors champ dans le film - et dans le dernier chant du chœur $(A M, 122$ et 158). En dehors d'une meilleure compréhension acoustique, cela permettait de segmenter vocalement une union apparente : les choreutes cessaient alors, l'un après l'autre, de tenir près de leur visage le masque dionysiaque, comme le montre une photo de scène $(A M, 124)$. On peut voir là aussi une métaphore scénique du théâtre épique brechtien où l'acteur et le personnage ne forment qu'une unité instable.

Mais la segmentation des répliques permettait surtout de faire ressortir des fragments de chant, comme c'est le cas dans le dernier $(A M, 158)$ : par la voix de l'un des choreutes s'en trouvent ainsi détachés les trois vers dans lesquels les Straub ont pu voir une incitation intertextuelle à choisir leur épilogue : « ... Abgehaun wird / Daß sie nicht zuschlag mehr / Uns die zwingbare Hand ». Ils laissent, quant à eux, au montage des plans le soin de déterminer les modalités visuelles des affrontements : il n'y a pas de champs/contrechamps traditionnels - l'échelle des plans et l'angle de prises de vues varie le plus souvent d'un plan à l'autre -, mais plutôt des variations qui concernent autant le statisme de la position des personnages sur la scène de Segesta que les arrière-plans. S'ils ne reprennent pas le découpage vocal brechtien, les Straub font dire la dernière réplique de la pièce (v. 1293-1303) par l'ensemble du chœur hors champ, voix encore une fois sans visages ni corps, que la caméra a délaissés dans un lent panoramique, qui fait fugacement rentrer dans le champ la servante-messagère ${ }^{47}$, avant de s'immobiliser, dans un plan général d'un mur de l'enceinte théâtrale en premier plan et de paysage à l'arrière plan : plan « vide » d'un peuple à venir qui est encore hors champ ${ }^{48}$ et ultime résonance d'une voix venue de l'antiquité et parfaitement actuelle dans un paysage peu transformé depuis cette même antiquité, mais qu'il ne faudrait pas prendre pour le cadre d'une histoire immuable. Le plan sera d'ailleurs immédiatement suivi de l'épilogue.

47. - Chez Sophocle et Hölderlin, c'est le messager qui dit la réplique de la servante, sinon absente du texte. Dans le film, c'est le seul personnage accroupi, mais dans une posture pleine de dignité (elle se redresse parfois), vêtu d'une ample robe, qui couvre aussi sa tête, du même ocre brun clair que celle d'Antigone. C'est peut-être la posture scénique appropriée pour faire transparaitre dans son récit le " point de vue des serviteurs [Gesinde] » voulu par Brecht qui en faisait un personnage fugace mais d'une substantialité populaire complexe : «Es soll der Genuß gezeigt werden, eine Katastrophe berichten zu dürfen, die respektvolle Gleichgültigkeit gegen den Herrn, die romantisierende Sympathie mit dem jungen Paar. » $(A M, 154)$.

48. - Absent de la scène de Chur et du film, le peuple doit se constituer dans la salle : «Frage : Welche Stellung einzunehmen soll dann das Publikum veranlaßt werden? Antwort : Die des Volks, das dem Zerwürfnis der Herrschenden zusieht. » $(A M, 118)$. 
La nouvelle relecture conjointe d'Antigone et du chœur des anciens infléchit la thématique de la dissolution de la dynastie des Labdacides décimée par la mort successive des enfants d'GEdipe (Étéocle et Polynice) et de ceux de Créon (Mégarée, Haimon), puis par la défection de Tirésias, « acolyte idéologique » (J., 12 janvier 1948) pressentant la fin et la révolte d'Antigone ${ }^{49}$. Plus que la disparition progressive d'une dynastie, dont nombre de mythologies font le cœur du tragique, ce sont les figurations du détachement du tyran et de la classe dominante que Brecht choisit de mettre en lumière. La guerre impériale et son corollaire, la guerre fratricide entre Étéocle, fidèle à Créon, et Polynice, prenant le parti d'Argos ${ }^{50}$, est un conflit fictionnel dans lequel Brecht a pu voir le symbole des deux Allemagnes sous le nazisme, Polynice pouvant figurer « 1'autre Allemagne », dont parlaient nombre d'exilés et que matérialisèrent l'engagement militaire de certains d'entre eux contre l'Allemagne nazie au sein du Nationalkomitee Freies Deutschland en URSS, de la résistance européenne ou des troupes alliées lors du débarquement de juin 194451 .

Plus on avance dans les ajouts brechtiens aux textes de Sophocle et Hölderlin dans cette grande confrontation entre Antigone et Créon, qui devient ici logiquement le meurtrier de Polynice, plus devient manifeste que la division fratricide de la fiction de base est métaphoriquement extensible aux deux camps qui divisèrent le peuple allemand entre 1933 et 1945 : ceux qui suivirent le «Führer »- ainsi est nommé parfois Créon - dans ses campagnes et ceux qui s'y refusèrent et finirent décapités à Plötzensee. La nouvelle Antigone focalise ainsi son argumentation sur les divisions du peuple suscitées par un tyran qui les exècre tellement qu'il est prêt à souhaiter aux Thébains « désunis » d'être dévorés par les vautours (v. 1286-88). Le tyran - Créon, mais aussi Hitler dont la Volksgemeinschaft exclut tous les « déviants » politiques ou raciaux - est celui qui proclame partout la nécessité de l'unité - surtout celle des dominants (v. 616-620) -, mais ne peut régner que

49. - Il subit, lui aussi chez Brecht, une « sécularisation » importante: « ... im alten Gedicht der Mitwisser göttlicher Voraussicht, ist (er) in der Bearbeitung ein guter Beobachter und deshalb in der Lage, einiges vorauszusagen $(G B F A, 24,351)$.

50. - Antigone énonce, envers Créon, la vision brechtienne des enjeux nazis: « Nicht genügte es dir / Über die Brüder zu herrschen in eigener Stadt / . . / . .du / Mußtest zum fernen Argos sie schleppen, über sie / Zu herrschen auch dort. Und machtest den einen zum Schlächter / Dem friedlichen Argos, doch den Erschrockenen / Legst du jetzt auch gevierteilt, zu schrecken die Eignen » (v. 411-419).

51. - La relecture brechtienne modifie donc radicalement la signification dramaturgique et idéologique du combat pour refuser ou imposer une sépulture décente à Polynice. La résistance d'Antigone n'est alors plus seulement dictée par la mise en conformité intransigeante avec des lois humaines immémoriales, mais par l'hommage à celui qui a su prendre les armes contre la tyrannie quitte à combattre les armées de sa propre patrie. 
par la désunion et l'exclusion meurtrière ${ }^{52}$. Attribuant cette désunion aux effets de la tyrannie locale qui chasse de larges fractions du peuple hors de leur patrie - «Weniger sind es geworden / In der Stadt, seit du herrschst, und werden noch weniger werden » (v. 453-454) -, Antigone remet en cause, du point de vue des dominés, la définition conservatrice et autoritaire que Créon donne d'une patrie ainsi épurée: «Nicht, wo einer Schweiß vergoß / Nicht das Haus, das hilflos dem Feuer entgegensieht / Nicht, wo er den Nacken beugt, nicht das heiß er Heimat » (v. 448-450). Pour ces exclus, le chez-soi, c'est souvent ce qu'il faut quitter : " Heimat ist das Entronnensein », dira Adorno qui, comme Brecht et un Jean-Marie Straub émigré en Allemagne pendant la guerre d'Algérie en 1959, a pu préférer s'en départir.

C'est peut-être aussi l'une des raisons pour lesquelles Brecht, ce rhétoricien-poète de l'Einverständnis - l' « importance d'être d'accord », peutêtre, mais plus sûrement la « compréhension de ce qui fait (ou défait) l'unité »-, a voulu faire d'Antigone la nouvelle figure emblématique de l'union et de la désunion dans un peuple, après l'avoir été dans sa propre famille, celle qui n'hésite pas à prendre le risque d'un effondrement de la tyrannie qui soit aussi celui de la cité53. En bonne logique, cette Antigone-là refuse radicalement l'impérialisme guerrier qui corrompt de larges couches des peuples et les entraîne dans des entreprises barbares et autodestructrices ${ }^{54}$. Lorsque Créon lie refus de dominer l'étranger et danger d'être soi-même détruit (v. 470-472), Antigone réplique : « Besser zwischen den Trümmern der eigenen Stadt / Säßen wir doch, und sicherer auch, als mit dir in den Häusern des Feinds ».

Dans le récit du messager, cette torsion des significations antiques permet de générer une constellation de sens parabolique : comme la guerre de conquête nazie, en particulier contre l'URSS, la défaite de Créon sonne comme le retournement de la Seconde Guerre mondiale après Stalingrad qu'il décrit avec des allusions précises à la pénétration thébaine « de plus en plus profonde dans une ville qui, dévastée, devint tombeau » (v. 1152-53). La description des aspects les plus concrets

52. - «Kreon : Uneins, so will sie uns haben unterm thebanischen Dach. / Antigone : Du, der nach Einigkeit schreist, vom Zwiste lebst du » (v. 430-431).

53. - « Die große sittliche Tat der Antigone, die sich gegen den Tyrannen Kreon auflehnt, besteht darin, daß sie, bewegt durch tiefe Menschlichkeit, nicht zögert, durch offenen Widerstand das eigene Volk in die Gefahr des Besiegtwerdens in einem Raubkrieg zu bringen (souligné par moi, A.C.) », écrit Brecht en 1951 (Hecht, 214-215).

54. - Aux intellectuels exilés qui, de plus en plus nombreux, « refusent de faire une différence entre les nazis et les Allemands », Brecht «propose », en 1942, de réviser leur vision du peuple pour comprendre le phénomène d'une adhésion aussi massive au fascisme hitlérien : "Faschismus ist eine Regierungsform, durch welche ein Volk so unterjocht wird, daß es dazu zu mißbrauchen ist, andere Völker zu unterjochen » $(J$., 28 juin 1942). 
de la bataille est incontestablement inspirée par ce que Brecht pouvait savoir de Stalingrad :

Doch das Gelände / Die Ausrüstung und Nahrung spielen auch mit. Und, Herr, das Argosvolk focht abgefeimt. / Die Weiber fochten und die Kinder fochten. /.../ Denn zu Schanzzeug / Und Waffe wurde Hausgerät und Wohnung (v. 1146-47).

C'est le balancement rhétorique de l'anadiplose qui traduit ici la mobilisation de tout un peuple contre l'envahisseur et la contre-attaque soviétique du printemps 1943, dont Brecht avait noté les développements dans son journal : "Und nicht mehr lang kann Thebe selber stehen, denn / Herauf kommt nun das Argosvolk mit Mann und Wagen auf allen Straßen. » (v. 1162-65).

On sait que le thème central de la désunion concerne, au début de la fiction grecque, Antigone et sa sœur Ismène. Une comparaison entre la mise en scène de Chur (qui joue le Vorspiel) et la première séquence du film des Straub montre comment en travailler les significations par l'image et le son. Le premier plan du film réunit d'abord les deux sœurs dans un plan moyen de biais, en posture statique, avec une cruche contenant le sable de la sépulture symbolique de Polynice. C'est le cadre divisé du «Gemeinsamschwesterliches! o Ismenes Haupt » initial de Hölderlin, formule à la polysémie rugueuse que Brecht allège en une triple adresse : « Schwester, Ismene, Zwillingsreis », tout en conservant l'image d'une communauté biologique qui ne vaut pas cause commune. Ce plan des deux sœurs immobiles, le pot de sable à proximité d'Antigone ${ }^{55}$, sera suivi de plans rapprochés de chaque sœur (plans 2 et 3), en très légère contre-plongée et sur fond de ciel, qui souligne la communauté dans la division ${ }^{56}$, Ismène étant hors champ à partir du plan 3. Dans le dialogue qui dit leur désunion, seule Ismène se tourne parfois vers Antigone qui regarde fixement devant elle avec une diction combative ${ }^{57}$, esquisse d'un contact maintenu dans le différend que va conclure la reprise du premier plan du film. La sortie séparée de ce plan - ce que la didascalie allemande du découpage ne précise

55. - Les photos de R. Berlau montrent une distance maximale entre les deux mais aussi, concrètement, le geste symbolique du sable recueilli par Antigone, que Brecht nomme «Staubaufsammelnde » (v. 37). Après avoir pénétré l'aire de jeu d'un pas rapide et léger, Antigone se met à genoux pour recueillir le sable dans un pot de fer, tandis qu'Ismène reste debout et immobile, à l'autre bout de l'aire de jeu.

56. - $C f$. la réplique de la double soumission d'Ismène, en tant que femme et que dominée : «Dies auch denke: Weiber sind wir / Und dürfen so nicht gegen Männer streiten /.../...da mir Gewalt geschieht / Folg ich dem Herrschenden. Vergebliches nämlich / Zu tun, ist unweis. » (v. 62-69).

57. - En opposition notable avec Helene Weigel à Chur, qui se « recroquevillait littéralement » face à « la volonté de sa sœur de se soumettre» $(A M, 92)$. 
pas alors que, curieusement, la «traduction » française en regard dit : « Ismène vers le palais, Antigone vers la ville » - introduit une différence topographique dont on peut inférer une forme de choix politique (plan 7, p. 18-19). Cette désunion, inscrite dans les plans à hauteur de personnage de cette première séquence ${ }^{58}$, inscrite aussi dans les six répliques hors champ d'Ismène, alors qu'Antigone parle toujours dans le champ, est un différend non antagonique, contrairement à celui qui opposera Antigone à Créon. Elle est visualisée dans le film, qui utilise pleinement le cadre naturel du théâtre de Segesta, par l'opposition entre la minéralité du personnage de Créon, presque toujours cadré sur fond de pierres, signe de pétrification humaine du pouvoir discrétionnaire, et une Antigone plutôt associée à l'organique, comme dans la grande scène de la confrontation avec Créon, où l'arbre devient tutélaire, seul dans le champ avec Antigone en plan rapproché (plan 50, 62-64).

Dans la séquence qui met en scène l'antagonisme entre les deux personnages principaux, ceux-ci ne sont jamais dans le même plan, à l'exception d'un rapide panoramique en plongée (plan 40) : c'est un balayage rapide du champ - du chœur à Créon, en passant par Antigone et le garde - qui visualise l'ensemble de l'espace où se joue l'antagonisme et, partant, la différence entre un traitement théâtral et une découpe cinématographique de la scène.

Dans cette séquence, par leur mimique et leur diction, Créon et Antigone sont en permanence des antagonistes irréductibles. Pas de « stupeur » chez le premier quand Antigone quitte la scène, comme à Chur $(A M, 112)$. Le conflit des répliques - avec quelques passages proches de la stichomythie - exhibe aussi les différences dans le jeu des protagonistes : le pouvoir expressif d'un acteur professionnel expérimenté comme Werner Rehm (Créon) - qui mobilise régulièrement mimique et gestuelle pour accentuer les signifiés de la diction ${ }^{59}$ - contraste avec le jeu plus statique d'Astrid Hofner (Antigone), alors jeune stagiaire de la Schaubühne. Sa diction est plus monocorde, bien

58. - Ils contrastent avec les nombreuses plongées et contreplongées des autres séquences. Par ailleurs, dans la grande scène/séquence de la confrontation entre Antigone et Créon, il y a alternance des répliques hors champ des protagonistes, sauf dans le plan 47, dans lequel Antigone énonce la contradiction principale. Sinon, la parole d'Antigone n'est quasiment jamais hors champ.

59. - Dans la scène de la confrontation avec son fils Hémon (plans 64-65), Créon manie le thyrse tantôt comme un sceptre (gestus du souverain), tantôt comme une lance (gestus du guerrier), gestuelle qui résume le sens principal de son personnage. Ce en quoi il détourne l'image, donnée par Brecht dans sa réécriture, du seul dieu qu'il conserve de la pléiade sophoclienne et hölderlinienne et dont il fait - après le grand cataclysme guerrier et contre une certaine vision post-nietzschéenne - le dieu de la joie de vivre, de la beauté et du règlement pacifique des conflits (v. 742-46), même s'il peut pousser les humains « à se courber sous le joug en espérant des plaisirs » $(G B F A, 24,352)$. 
que fortement scandée et soulignée par un mouvement volontaire constant de la tête. On peut aussi voir là, comme Byg et Steiner ${ }^{60}$, une séparation volontaire et signifiante de la diction du détenteur du pouvoir et de celle qui le subit, une sorte de « code sémantique » (Steiner) de la parole scénique où se concrétise physiquement l'antagonisme principal de la pièce.

Toutes ces significations politiques complexes exigent un rapport et un traitement particuliers du langage poétique le plus dense dont les Straub se sont fait une spécialité. Le prologue brechtien de 1951 avertit le spectateur : il sera ici en pays linguistique étranger : « Freunde, ungewohnt / Mag euch die hohe Sprache sein / In dem Gedicht, tausende Jahre alt / Das wir hier einstudiert. » $(G B F A, 8,242)$. Mais cette « langue noble » n'est pas celle de Sophocle. Elle est plutôt celle de Hölderlin que Brecht a choisi, dit-il, pour ses obscurités et son « gestus populaire souabe » $(J, 25$ décembre 1947). Ce serait donc l'alliance paradoxale d'une langue de la grande poésie réputée hermétique et de l'habitus langagier du petit peuple, le tout articulé sur des « constructions latines apprises au lycée $» 61$, bref la langue dialecticienne de la distanciation. Opposée au «pathos sonore » d'un théâtre du «mélange inextricable des styles » de l' « époque de la grande braderie », celle du nazisme $(A M, 80)$, une telle langue doit faire entendre une musicalité rugueuse et dissonante ${ }^{62}$ pour faire émerger la dimension " gestique » du texte mis en voix. Brecht et les Straub donnent ainsi à entendre les nombreuses hypotaxes des répliques de Créon comme le revers d'une même médaille : la diction aristocratiquement ampoulée du pouvoir sait, à l'occasion, être triviale ${ }^{63}$. L'objectif du travail sur la versification de la « grande langue » était donc de la contraindre à révéler l'état conflictuel des relations humaines :

Es handelte sich [...] nicht nur um [...] einen Protest gegen die Glätte und Harmonie des konventionellen Verses, sondern immer doch

60. - Cf. Byg, op. cit., p. 222.

61. - « Ich finde schwäbische Tonfälle und gymnasiale Lateinkonstruktionen und fühle mich daheim. Auch Hegelisches ist da herum. Vermutlich ist die Rückkehr in den deutschen Sprachbereich, was mich in das Unternehmen treibt. » (J., 16 décembre 1947).

62. - $C f$. l'ouvrage de D. Baldo, qui fait une grande part à l'interprétation idéologique des caractéristiques formelles de la langue poétique de Brecht comme langue « gestique »-versification, césures, rythmes etc.

63. - On peut y voir le gestus linguistique fondamental d'un pouvoir tyrannique, fictionnel (Créon mais aussi Arturo Ui) ou réel (Hitler). « Spricht der Sophokleische Kreon noch vorwiegend als aristokratischer Repräsentant des Staates, so kennzeichnet die Sprachgestaltung Brechts ihn als unberechenbaren Tyrannen : mitunter redet er extrem drastisch und primitiv, wie einer, der sich aus der Gosse emporgearbeitet hat... » (Rainer Pohl, « Strukturelemente und Pathosformen in der Sprache», op. cit., p. 250). 
schon um den Versuch, die Vorgänge zwischen den Menschen als widerspruchsvolle, kampfdurchtobte, gewalttätige zu zeigen ${ }^{64}$.

Brecht le réaffirmera dans le Antigonemodell : il faut que «quelque chose de contradictoire entre dans l'écoulement des vers » $(A M, 124)^{65}$ qui batte en brèche les lissages de la diction classique et du « grand style ».

Le film des Straub et la traduction de D. Huillet dans le découpage publié manifestent en permanence qu'un tel traitement langagier, que la prise de son exemplaire de Louis Hochet fait entendre à chaque plan dans la diction des acteurs, repose lui aussi sur la ferme conviction que s'y révèle la dimension éminemment politique du texte. On peut prendre ici l'exemple des césures, si importantes pour Hölderlin et Brecht pour leur aptitude à accroître le rythme poétique, mais aussi dramaturgique 66 . Dans ses « Remarques sur Edipe », le premier y voyait « une interruption à contre-rythme » qui libérait « le mot pur » et permettait « le changement torrentueux des représentations » (Beissner, 214). Comme à leur habitude, les Straub respectent systématiquement celles des césures qui marquent graphiquement la fin d'un vers. Pour eux comme pour Brecht : «La fin d'un vers signifie toujours une césure »67. Aux césures phoniques s'ajoutent, chez les Straub, les césures typiquement cinématographiques que représente l'acoutismatisation (M. Chion) des voix dans les répliques hors champ. La césure ici, c'est d'abord la disparition de l'image quand la seule voix assure la continuité dialoguée et exige du spectateur une perception clivée de l'image et des sons.

Pour Hölderlin, il y avait, par ailleurs, une force quasiment mortifère de la langue tragique grecque en tant qu'elle était aussi action : « das griechischtragische Wort ist tödlichfaktisch, weil der Leib, den es ergreift, wirlich tötet ${ }^{68}$. Les Straub sont ici très proches du poète souabe quand ils écrivent dans le programme de la Schaubühne que la parole tragique " est mortelle, c'est une mort physique ». Une scène du film, conforme à une didascalie ajoutée par Brecht, en est la démonstration la plus littérale : celle du récit du messager. Quand la

64. - B. Brecht, « Über reimlose Lyrik mit unregelmäßigen Rhythmen », in : Gesammelte Werke, Bd. 19, Frankfurt am Main, Suhrkamp, 1967, p. 397.

65. - Les Straub citent ces remarques sur la versification dans le programme de la représentation de la Schaubühne. Dans des remarques à la fois proches des Anmerkungen zur Antigone d'Hölderlin et des réflexions de Brecht, Hans Curjel note dans le programme de celle de Chur : «Die rhythmische Aufteilung Hölderlins ist beibehalten, ja in ihrer Strenge und Unerbittlichkeit gesteigert. » (Hecht, 124).

66. - « Die Pausen [...] unterteilen die Verse in Handlungsblöcke und spielbare Einheiten. Sie lenken das Geschehen und machen die Zuschauer auf bestimmte Haltungen der beiden Schwestern aufmerksam. » (D. Baldo, op. cit., p. 148).

67. - «Über reimlose Lyrik mit unregelmäßigen Rhythmen », op. cit., p. 401.

68. - Beissner, 293. 
langue énonce la défaite et la mort, elle tue l'énonciateur qui en fut le témoin terrifié : «Und ich, der's gesehen / Ist froh, daß er schon hin ist. Er stirbt » (v. 1165-66) ${ }^{69}$.

On pourrait, en conclusion, retenir ce dernier plan général de l'apparition filmique d'Antigone face à la posture pétrifiée du chœur, se dirigeant d'un pas léger et la robe flottante vers son arbre tutélaire et le contournant, comme lors de sa première sortie de scène. Dans le plan rapproché de profil qui précède, ses boucles d'oreilles pendantes se balançaient au rythme de l'obstination saccadée de la diction qui éclairait son visage. C'était un mouvement proprement « gestique », qui disait la non-réconciliation avec le pouvoir criminel et la tristesse courroucée de la mort imminente, en contraste léger avec le mouvement naturel du vent qu'on voit faire frissonner le feuillage du micocoulier en arrière-plan et qui pourrait avoir ici une fonction de sous-texte (ou de « sous-image »). Les Straub placeront Créon presqu'exactement en cette place d'Antigone lors de son ultime réplique qui est l'antithèse de celle de la fille d'Edipe, comme le soulignent les crispations brutales de sa mimique, de sa gestuelle et de sa voix. C'est aussi un corps plus raide et plus lourd qui quitte une scène identique mais qui n'est pas commune, corps solitaire que Brecht faisait soutenir par les servantes d'Antigone à Chur ${ }^{70}$, qui disparaît en restant dans la négativité du mythe, celui d'un pouvoir barbare et inhumain jusqu'au bout, et non un corps léger entrant dans l'espace d'une histoire autre, qui aurait sans cesse à réitérer le gestus antagonique de la résistance. S'il y a dans la pièce un « être pour la mort » (Heidegger), il est illustré par la sortie de scène de Créon, en écho à son dernier souhait de voir sa patrie disparaître avec lui $(G B F A, 24,350)$ et être la proie des vautours (v. 1286-88).

Des premières interprétations du personnage par Brecht à sa métamorphose dans des répliques où s'affine et se renforce cette résistance à un ordre établi qui perdure de Créon à Hitler, de la petite scène de Chur aux grands espaces ensoleillés de Segesta, Antigone devient ainsi cette

69. - À Chur, le récit du refus de sépulture et des massacres dans les propres rangs des Thébains (v. 1124-31) est prononcé à voix « très basse », et le déferlement des défenseurs d'Argos (v. 1160-62) à voix « considérablement plus haute » $(A M, 155)$. Il n'y a pas de rupture de tonalité dans le film, mais une césure visuelle : le récit du messager est presqu'entièrement hors champ (plan 132) et proféré d'un bout à l'autre d'une voix forte, pleine de pathos tragique et de colère. Il n'y a pas non plus de jeux mortuaires rituels avec les accessoires (masques, couronnes, thyrses), comme à Chur $(A M, 151)$.

70. - Pourtant, les Straub ne rigidifient pas le corps de Créon : avec des parements géométriques qui peuvent connoter une magnificence du pouvoir, sa vêture est, elle aussi, ample et flottante, plus proche de la djellaba arabe que du chiton de lin et a fortiori du péplos drapé des anciens Grecs. 
belle figure d'un beau poème éponyme dédié à Helene Weigel, poèmeprologue écrit pour la première représentation de la pièce :

Komm aus dem Dämmer und geh / Vor uns her eine Zeit / Freundliche, mit dem leichten Schritt / Der ganz Bestimmten, schrecklich / Den Schrecklichen. / ... / Abgewandte, ich weiß / Wie du den Tode gefürchtet hast, aber / Mehr noch fürchtetest du / Unwürdig Leben. / Und ließest den Mächtigen / Nichts durch, und glichst dich / Mit den Verwirrern nicht aus, noch je / Vergaßest du Schimpf und über der Untat wuchs / Ihnen kein Gras ${ }^{71}$.

71. - B. Brecht «Antigone », in : Gesammelte Werke Bd. 10, Frankfurt am Main, Suhrkamp, 1967, p. 954. 